\title{
POLÍTICAS PÚBLICAS DOS RECURSOS HÍDRICOS NO DESENVOLVIMENTO DA AGRICULTURA IRRIGADA
}

Fernando Ferrari Putti ${ }^{1}$

Pedro Fernando Cataneo ${ }^{2}$

\section{Camila Pires Cremasco Gabriel ${ }^{3}$}

\section{Luís Roberto Almeida Gabriel Filho ${ }^{4}$}

RESUMO: $O$ aumento da população vem demandando o aumento na produção de alimentos, em que a inserção de tecnologias no campo já alcança deste o pequeno produtor rural até os grandes latifundiários, e uma tecnologia que se destaca é a irrigação. Assim, o objetivo do trabalho foi realizar uma revisão sobre as politicas publicas dos recursos hídricos na irrigação. Em que são diversos órgãos públicos que gerenciam o uso de água pela agricultura, e vem destacando o estudo para se calcular a questão de água virtual exportada pelos países e suas consequências.

Palavras-chave: Sustentabilidade. Energia. Biocombustíveis. Políticas públicas

\section{INTRODUÇÃO}

\footnotetext{
${ }^{1}$ Mestrando em Agronomia (Irrigação e Drenagem), UNESP/FCA- Botucatu. Email: fernandoputti@fca.unesp.br.

${ }^{2}$ Mestre e Doutor em Agronomia, Prof. Doutor, UNESP - Univ Estadual Paulista, Tupã-SP, UNESP,

${ }^{3}$ Mestre em Matemática, Doutora em Agronomia, Pós-Doutora em Biometria, Profa. Doutora, FATEC Faculdade de Tecnologia de Presidente Prudente, e FCA/UNESP, Botucatu - SP,camila@fatecpp.edu.br ${ }^{4}$ Mestre em Matemática, Doutor e Pós-Doutor em Agronomia, Prof. Doutor, UNESP - Univ Estadual Paulista, Tupã-SP, e FCA, UNESP, gabrielfilho@tupa.unesp.br.
} 
O contexto desenvolvimento sustentável vem ganhado destaque no cenário internacional, assim busca-se o equilíbrio entre crescer e não alterar as condições do meio ambiente. E nesse sentido com o aumento da população sendo cada vez maior, tem-se a preocupação com a necessidade de se aumentar a produção de alimentos.

Porém sabe que a terra agricultável existente no mundo está sendo utilizada sem devidos cuidados, além disso, as terras apropriadas estão quase totalmente ocupadas por plantações. Nesse sentido uma forma de aumentar a produção, é inserção de tecnologias para alavancar as produções.

Essas tecnologias vão deste a semente até o pós-colheita. Mas no contexto atual, os métodos de irrigação estão se tornando cada vez mais eficientes e consequentes resultados positivos no aumento da produtividade no campo.

Entretanto, a irrigação é considerada a "vilã" no consumo de água no mundo, pois se demanda um consumo muito grande não apenas na produção, mas também no processamento de produtos agroindustriais.

O governo vem adotando medidas para controlar o uso de água na agricultura, através de politicas deste o incentivo na conservação de nascentes de água até o uso responsável.

Dento do contexto apresentando, objetivo do trabalho foi realizar uma revisão sobre as politicas publicas dos recursos hídricos na irrigação no Brasil.

\section{MATERIAIS E MÉTODOS}

O principal método de pesquisa que foi utilizado constitui do tipo exploratório, onde ocorreu um levantamento de dados e através de pesquisas qualitativa se poderiam estabelecer a relação entre dados numéricos e sua possível influência na esfera política, social e econômica.

Para a realização deste trabalho, teve como principal fonte bibliográfica a Agência Nacional das Águas, em que disponibilizou material didático, assim como informações sobre $o$ assunto abordado.

\section{RESULTADOS E DISCUSSÕES}




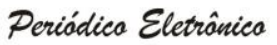

\section{Água no contexto mundial.}

Como sabemos a água se torna algo indispensável para a existência de vida na terra, e atualmente no nosso planeta a quantidade de água existente corresponde a $3 / 4$ de toda a superfície, ou seja, seu volume é em torno de 523 milhões de $\mathrm{Km}^{3}$, desse valor total, aproximadamente 97 \% estão nos oceanos e mares, 2,2\% está em forma de gelo, que são as geleiras polares e geleiras montanhosas e apenas $0,6 \%$ corresponde às águas de rios, lagos e lençóis subterrâneos, e que são apropriadas para o consumo humano.

Segundo a FAO em torno de $80 \%$ da população mundial vive em áreas que o abastecimento de água potável não é assegurado, ou seja, 3,4 milhões de pessoas enfrentam as piores ameaças com a falta de água.

E para dificultar ainda mais o abastecimento de água, estima-se que $30 \%$ da água doce da terra que seria disponível esta no subsolo.

No Brasil encontra-se um dos maiores aquíferos do planeta, o Aquífero Guarani, e só para dimensionar, hoje em dia $75 \%$ dos municípios do interior do estado de São Paulo, necessita da água proveniente para o abastecimento, podemos citar como exemplo o caso da cidade de Ribeirão Preto, que $100 \%$ da água que abastece a cidade provem dos aquíferos.

\section{Política Pública}

O termo Políticas Públicas é muito recorrente ao nosso dia-a-dia, para, se tratam de princípios norteadores de ação do poder público, regras e procedimentos para as relações entre poder público e sociedade e ampara as mediações entre atores da sociedade e do estado, ou seja, são os "outputs" resultantes da atividade política que compreendem o conjunto de decisões e ações relativas a alocação imperativa de valores (TEXEIRA 2002).

- Podemos ressaltar como as principais funções:

- Planejamento ou concepção ou formulação das políticas;

- Orçamento ou alocação de recursos para viabilização das políticas; 
- Execução ou a implementação ou a operacionalização das medidas para a realização das políticas públicas;

\section{Irrigação}

O produtor que se utiliza da irrigação deve realizar um estudo e acompanhar dia a dia sua cultura, pois é preciso saber quando irrigar e a quantidade de água a ser aplicada, pois sua falta ou excesso pode prejudicar o desenvolvimento de lavoura e consequentemente prejudicar sua produção.

A utilização adequada da irrigação pode proporcionar alavancagem na produção, e consequência pode aumente a receita líquida, diminuição das incertezas e o comprometimento com o fornecimento (BERNADO 1987).

E umas das questões que mais se discute em relação à irrigação é sua capacidade em afixar populações em determinas regiões.

Segundo dados do o Brasil apresenta apenas $6,3 \%$ de suas propriedades que utilizam a irrigação, e em toda a área agricultável do país $7,4 \%$ detém algum tipo de sistema de irrigação, que gira em torno de 4,45 milhões de hectare.

A Figura 1 apresenta a porcentagem que cada sistema de irrigação é utilizado no Brasil, onde podemos observar que a aspersão e inundação são as mais utilizadas para a irrigação.

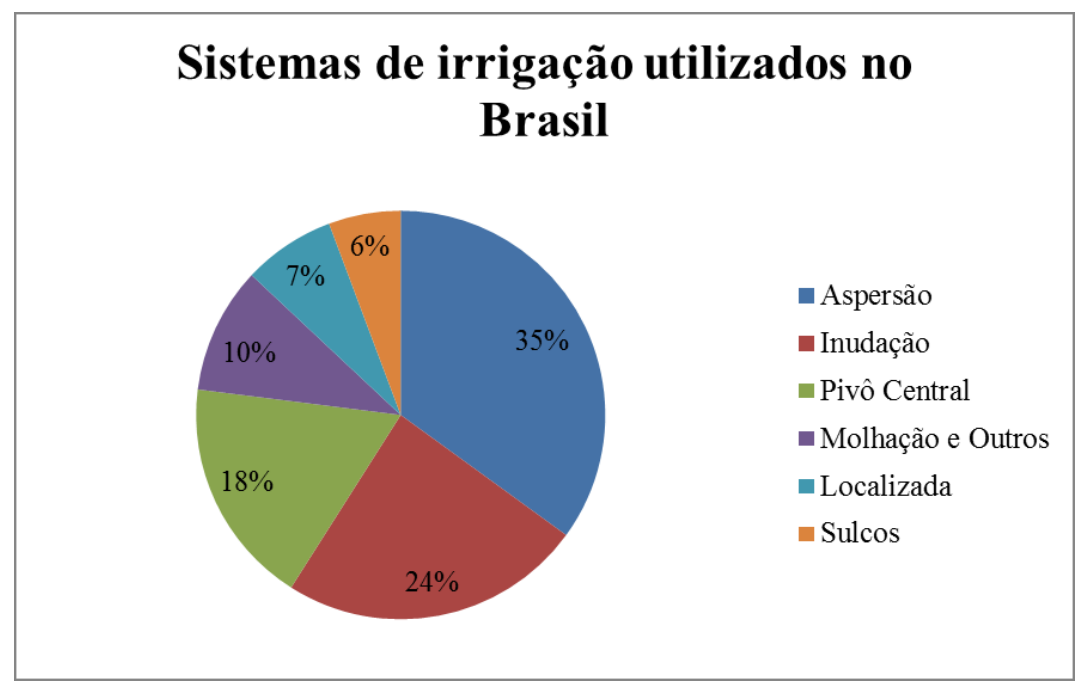

Figura 1: Sistemas de irrigação utilizados no Brasil. Fonte: Censo Agropecuário/IBGE (2006). 
O método de aspersão apresenta o maior uso, mas sua área irrigada ainda é menor, pois devido a grande plantações de arroz no Rio Grande do Sul (CENSO AGROPECUÁRIO 2006), a método de sulcos apresenta a maior área irrigada, como podemos observas na Figura 2.

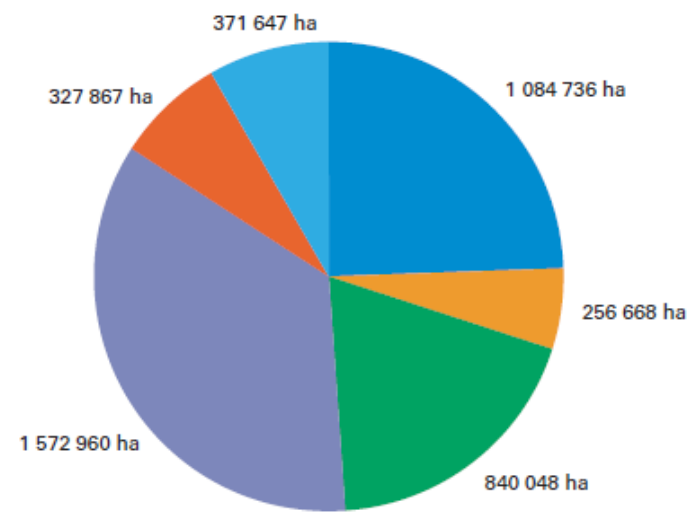

Figura 2: Área irrigada por método de irrigação no Brasil. Fonte: Censo Agropecuário / IBGE (2006).

\section{Objetivos das Políticas Públicas dos Recursos Hídricos.}

O principal objetivo das Políticas Públicas dos Recursos Hídricos no Brasil é equilibrar a tensão que existe entre o desenvolvimento de uma determinada região e seus impactos no meio ambiente, pois bem sabemos que água é um recurso essencial nas indústrias e também para o saneamento da população, assim como a água é responsável por mais de $90 \%$ da produção de energia em nosso país. Esse equilíbrio tem que ser mantido para que possa ocorrer o múltiplo uso da água, que está ilustrada na Figura 3. 


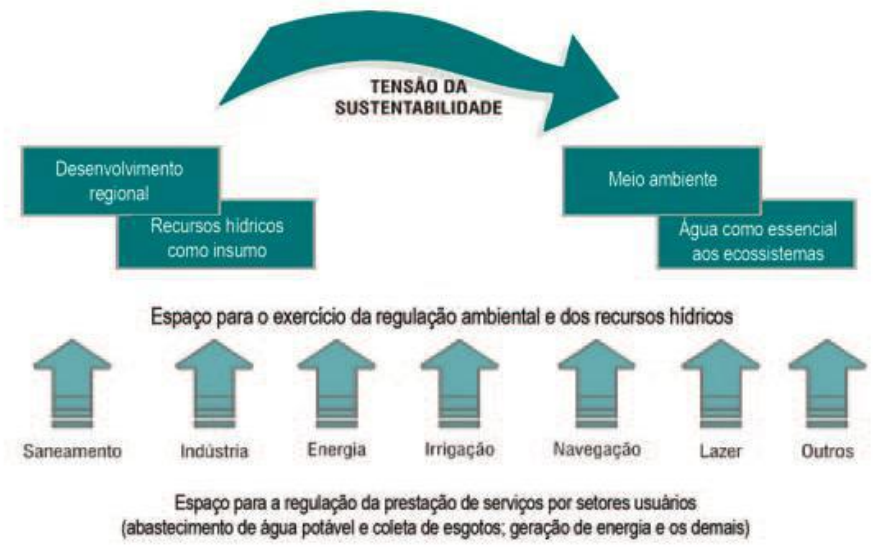

Figura 3: Objetivos das Políticas Públicas. Fonte: Plano Nacional de Recursos Hídricos (2006).

\section{Órgãos responsáveis.}

\section{Conselhos}

O Conselho Nacional de Recursos Hídricos desenvolve atividades desde junho de 1998, ocupando a instância mais alta na hierarquia do Sistema Nacional de Gerenciamento de Recursos Hídricos, instituído pela Lei ㄲo 9.433, de 8 de janeiro de 1997. É um colegiado que desenvolve regras de mediação entre os diversos usuários da água sendo, assim, um dos grandes responsáveis pela implementação da gestão dos recursos hídricos no País. Por articular a integração das políticas públicas no Brasil é reconhecido pela sociedade como orientador para um diálogo transparente no processo de decisões no campo da legislação de recursos hídricos.

Possui como competências, dentre outras:

- Analisar propostas de alteração da legislação pertinente a recursos hídricos;

- Estabelecer diretrizes complementares para implementação da Política Nacional de Recursos Hídricos;

- Promover a articulação do planejamento de recursos hídricos com os planejamentos nacional, regionais, estaduais e dos setores usuários;

- Arbitrar conflitos sobre recursos hídricos; 
- Deliberar sobre os projetos de aproveitamento de recursos hídricos cujas repercussões extrapolem o âmbito dos estados em que serão implantados;

- Aprovar propostas de instituição de comitês de bacia hidrográfica;

- Estabelecer critérios gerais para a outorga de direito de uso de recursos hídricos e para a cobrança por seu uso;

- Aprovar o Plano Nacional de Recursos Hídricos e acompanhar sua execução.

\section{Ministério do meio ambiente}

O Ministério do Meio Ambiente (MMA), criado em novembro de 1992, tem como missão promover a adoção de princípios e estratégias para o conhecimento, a proteção e a recuperação do meio ambiente, o uso sustentável dos recursos naturais, a valorização dos serviços ambientais e a inserção do desenvolvimento sustentável na formulação e na implementação de políticas públicas, de forma transversal e compartilhada, participativa e democrática, em todos os níveis e instâncias de governo e sociedade.

\section{Agência Nacional das Águas}

A Agência Nacional de Águas tem como missão programar e coordenar a gestão compartilhada e integrada dos recursos hídricos e regular o acesso à água, promovendo o seu uso sustentável em benefício da atual e das futuras gerações. Além disso, a instituição possui outras definições estratégicas centrais.

\section{Comitês das bacias}

Os Comitês de Bacia Hidrográfica são organismos colegiados que fazem parte do Sistema Nacional de Gerenciamento de Recursos Hídricos e existem no Brasil desde 1988. A composição diversificada e democrática dos Comitês contribui para que todos os setores da sociedade com interesse sobre a água na bacia tenham representação e poder de decisão sobre sua gestão. Os membros que compõem o colegiado são escolhidos entre seus pares, sejam eles dos diversos setores usuários de água, das organizações da 
sociedade civil ou dos poderes públicos. Suas principais competências são: aprovar o Plano de Recursos Hídricos da Bacia; arbitrar conflitos pelo uso da água, em primeira instância administrativa; estabelecer mecanismos e sugerir os valores da cobrança pelo uso da água; entre outros.

\section{Agência Nacional das Águas}

A criação da Agência Nacional está regulamentada pela Lei № 9.984, de 17 de julho de 2000 a qual se dispõe sobre a criação da mesma, que se trata de uma entidade de fomento federal de implementação da Política nacional de Recursos Hídricos e de coordenação do Sistema nacional de Gerenciamento de recursos Hídricos e de outras providências.

Onde visa destacar as funções que são delegadas, as quais são a de regulamentação do uso das águas dos rios e lagos de domínio da União e implementar o Sistema Nacional de Gerenciamento de Recursos Hídricos.

Em que apresenta a função de projetar a garantia de seu múltiplo uso, de forma sustentável, evitando a poluição e o desperdício e assegurar, para o desenvolvimento do país, água de boa qualidade e em quantidade para a atual e as futuras gerações.

A ANA apresenta entre outras funções, o cuidado de supervisionar, controlar e avaliar a Política de Recursos Hídricos, disciplinar em caráter normativo a implementação, a operacionalização, o controle e a avaliação dos instrumentos da Política Nacional de Recursos Hídricos, e de outorgar por intermédio de autorização o direito de uso de recursos hídricos em corpos de domínio da União, planejar e promover ações destinadas a prevenir ou minimizar os efeitos de secas e inundações, arbitrar conflitos de interesses, estimular a criação dos Comitês, viabilizar a efetiva participação dos Agentes e por fim de alocar a água como forma sustentável e zelar pela sua conservação.

\section{Outorga do direito do uso da água.}

Para a utilização de água tanto superficial quanto sub-superficial existentes normas a serem seguidas, neste caso observa que a ANA autoriza a utilização de até 4 litros por segundo, após este valor será necessário a autorização através da outorga, por 
exemplo, o estado de São Paulo que apresenta um comitê próprio que é o Departamento de água e esgoto, permite apenas o uso sem restrição de 1 litro por segundo ou a construção de reservatórios de até 3.000 metros cúbicos ou de tanques em várzea de até 5.000 metros quadrados.

Se o proprietário retirar quantidades superiores a permitida deverá realizar o pedido da à outorga que se trata de um instrumento regulador que busca o ordenamento dos usuários de recursos hídricos, dentro de uma lógica sistêmica dentro de um mesma bacia de modo a evitar os conflito, a garantir o seu múltiplo uso e sua sustentabilidade e o uso racional.

E no caso de mais de uma obra que aja a necessidade de outorga, deverá ser encaminhado os pedidos juntos ao órgão responsável.

A outorga é tratada na Lei $N^{\circ} 9.433 / 1997$, como um dos seis instrumentos da Política Nacional de Recursos Hídricos que tem segundo a legislação tem o objetivo de assegurar o controle quantitativo e qualitativo do uso da água e o efetivo exercício do direito de acesso a ela:

- As Políticas Nacionais de Recursos Hídricos se baseia nos seguintes fundamentos:

- A água é um bem público;

- A água é um recurso natural limitado dotado de valor econômico;

- Em situação de escassez, o uso prioritário dos recursos hídricos é o consumo humano e a dessedentação de animais;

- A gestão dos recursos hídricos deve sempre proporcionar o uso múltiplo das águas.

\section{Pegada da água virtual}

A água virtual vem sendo bastante utilizada entre pesquisadores, que se trata de uma ferramenta para quantificar a água total gasta para se produzir um produto ou um bem de consumo. Na década de 90, o conceito foi introduzido cientista e professor John Anthony Allan (CARMO et al. 2005) e apenas em 2008 foi homenageado com o "Prêmio da Água de Estocolmo 2008 - 2008 Stockholm Water Prize". 
Em 2002, Arjen Y. Hoekstra e colaboradores utilizando o conceito da água virtual e da pegada ecológica chegaram à teoria da "Pegada da Água". Descrevendo-a como o volume de água virtual que é consumida pelos habitantes de uma localidade (HOEKSTRA; CHAPAGAIN, 2007).

Carmo et al. (2005), explicam que a água virtual diz respeito principalmente ao comércio indireto da água que está embutida em certos produtos, especialmente as commodities agrícolas, enquanto matéria-prima intrínseca desses produtos, ou seja, toda água envolvida no processo produtivo de qualquer bem industrial ou agrícola, passa a ser denominada água virtual. E a movimentação dessas commodities ou bem industrial através do comercio entre os locais consumidores e produtores, forma a Pegada da Água pelo Mundo.

Para calcular a Pegada de Água de um país, se se refere aos recursos hídricos do país utilizado para produzir os bens e serviços consumidos pelos seus habitantes, enquanto que a Pegada de Água Externa aponta a quantidade de recursos hídricos utilizados em outros países para produzir os bens e serviços que são posteriormente consumidos por habitantes do país (HOEKSTRA; CHAPAGAIN, 2007).

\section{CONCLUSÃO}

No contexto apresentado, a discussão sobre o uso racional da agua na produção agrícola, está se tornando algo rigoroso por parte dos agentes competentes. Destaca-se a criação da ANA como sendo um grande para regular o uso da água.

Assim, observa-se que ainda existem lacunas que demandam atenção e principalmente a atenção de produtores em relação às leis vigentes, pois no estado de São Paulo, em que as normas existentes já regulam a retirar de águas nos rios.

E ainda, deve-se se destacar a importância da questão da exportação de água virtual existente. Em que se acumula ao longo dos processos produtivos, e muitas vezes tornam a água de boa qualidade, em uma água que não pode ser utilizada para consumo.

\section{REFERÊNCIAS}


ANA. AGÊNCIA NACIONAL DE ÁGUAS. Disponível em <http://www.ana.gov.br. Acesso em 15 de março de 2012.

BRASIL. Política Nacional de Recursos Hídricos. Lei n 9.433 de 08 de janeiro de 1997. Disponível em:<http://www.planalto.gov.br/ccivil_03/leis/L9433.htm>. Acesso em: 15 de março de 2012.

BRASIL. Criação da Agência Nacional de Águas - ANA. Lei no 9.984, de 17 de junho de 2000. Disponível em <http://www.planalto.gov.br/ccivil_03/leis/L9984.htm>. Acesso em 15 de março de 2012.

CARMO, R.L.; OJIMA, A.L.R.O. ; OJIMA, R. Água virtual e desenvolvimento sustentável: o Brasil como grande exportador de recursos hídricos. ANAIS... XXV CONGRESO DE LA ASOCIACIÓN LATINOAMERICANA DE SOCIOLOGIA. Porto Alegre, 2005.

FAO. Disponível em http://www.fao.org/. Acessado em 15 de março de 2012.

\section{FILHO, C. J. M. Curso de Capacitação de Técnicos Municipais para Elaboração de} Planos Diretores, 2005.

HOEKSTRA, A.Y.; CHAPAGAIN, A.K. Water footprint of nations: Water use by people as function of their consumption pattern. Water Resources Management 21. p.35-48. 2007.

IBGE. Censo Agropecuário 2006. Disponível em < http://www.ibge.gov.br/home/estatistica/economia/agropecuaria/censoagro/2006/default.s $\mathrm{htm}>$. Acesso em 15 de março de 2012.

LANNA, A. E. L. Gerenciamento de bacia hidrográfica: aspectos conceituais e metodológicos. Brasília: IBAMA, 1995. 171 p.

SETTI, A. A., LIMA, J. E. F. W., CHAVES, A. G. de M., PEREIRA,. Introdução ao gerenciamento de recursos hídricos. $2^{\mathrm{a}}$ ed. - Brasília: Agência Nacional de Energia 
Elétrica, Superintendência de Estudos e Informações Hidrológicas, 2000. 207 p.: il.: 23 $\mathrm{cm}$.

SILVA, J. A. Gestão de recursos hídricos e sistemas de informações geográficas: contribuições para a organização sócio espacial do Pontal do Paranapanema - SP. Dissertação (Doutorado). Presidente Prudente: UNESP, 2006.

TEIXEIRA, E, C. O Papel das Políticas Públicas no Desenvolvimento Local e na Transformação da Realidade. AATR-BA, 2002. 